\title{
PERTUMBUHAN DAN HASIL KUBIS BUNGA PADA SISTEM HIDROPONIK SUBSTRAT DENGAN MEDIA BAGASE
}

Ade Imam Mustofa ${ }^{1)}$, Djoko Purnomo ${ }^{2)}$, Amalia Tetrani Sakya2)

1. Undergraduate Student of Study Program of Agrotechnology, Faculty of Agriculture, University of Sebelas Maret (UNS) in Surakarta

2. Lecturer staff of Study Program of Agrotechnology, Faculty of Agriculture, University of Sebelas Maret (UNS) in Surakarta

Kontak Penulis: adeimammustofa@gmail.com

\section{ABSTRACT}

Cauliflower is one of the popular vegetables and has high economic potential. The need for vegetables is high but the productivity is increasingly starting to decline due to narrow land. Hydroponic technology does not require fertile are. Hydroponics of cauliflower expected to increase economic value. Bagasse has characteristics wet and easy to absorb water is very suitable as a media hydroponic substrate. The experimental research was held out from August 2016 until February 2017 in the screen house of the Faculty of Agriculture, Sebelas Maret University, Surakarta The experiments using complete randomized design with 2 treatment factors consisted of various nutrients (2 types) and media (3 types) resulting in 6 treatment combinations, each repeated 3 times. Nutrient types are standard nutrients and modified nutrients (standard $\mathrm{K}$ reduction nutrients). The types of media types are bagasse, bagasse + gravel, and bagasse + red brick fractions. Bagasse + fragment red brick showed better yield on volume of root, large of leaf, biomass of plant and age of flower. While the highest of plant on media bagasse + gravel.

Keywords: Large Of Leaf, Diameter Of Flower, Age Of Flowering, Biomass

AGROTECHNOLOGI RESEARCH JOURNAL

Mustofa AI, Purnomo D, Sakya TA. 2017. Growth and Yield of Cauliflower on hidroponic Substrate System with Bagasse Media. Agrotech Res J 2(1): 6-10.

Mustofa Al, Purnomo D, Sakya TA. 2017. Pertumbuhan dan Hasil Kubis Bunga Pada Sistem Hidroponik Substrat Dengan Media Bagase. Agrotech Res J

\section{PENDAHULUAN}

Peningkatan jumlah penduduk menyebabkan bertambahnya kebutuhan tempat tinggal. Pembuatan perumahan pada lahan pertanian produktif mengakibatkan kurangnya lahan subur dan penurunan produktivitas pangan. Untuk itu perlu adanya inovasi teknologi untuk dapat memcahkan masalah tersebut. Hidroponik adalah salah satu teknologi pemecahan masalah tersebut karena dapat dilakukan tanpa tergantung dengan ketersediaan lahan subur

Hidroponik adalah salah satu teknologi budidaya tanaman tanpa menggunakan tanah sebagai media pertumbuhan dan menggunakan larutan sebagai penyuplai nutrisi pada tanaman. Media yang seharusnya menggunakan tanah dapat diganti dengan menggunakan pasir, sekam arang, zeolit, bagase dan lain-lain. Substrat tersebut diketahui juga memiliki kemampuan sama seperti tanah dan mampu untuk menjadi media tanam (Harjoko 2009). Teknologi hidroponik dapat menggunakan lahan tidak subur bahkan tanah yang sudah tertutup beton dapat dimanfaatkan. Tidak seperti menanam secara konvensional, pada hidroponik ketersediaan hara (makro maupun mikro) harus dirancang sesuai kebutuhan.

Bagase memiliki karakteristik basah dan cepat menyerap air. Kandungan $\mathrm{C}$ (Karbon) tinggi dan $\mathrm{K}$ $\left(\mathrm{K}_{2} \mathrm{O}\right) \quad 0,14 \%$ (Samsuri et al 2007) sangat cocok sebagai media hidroponik. Penggunaan media organik

*Fak. Pertanian UNS Surakarta

JI. Ir. Sutami 36 A Surakarta juga diperlukan dalam substrat hidroponik untuk dapat mendukung kapasitas drainase dan aerasi pada media organik. Krikil dan pecahan batu bata merupakan media anorganik memiliki karakteristik drainase yang baik dan memiliki pori-pori besar, sehingga dapat mendukung media organik yang cenderung memiliki pori kecil. Kondisi media dengan pori makro dan mikro seimbang dapat menjaga kebutuhan air dan oksigen. Tujuan penelitian adalah mempelajari penggunaan bagase sebagai substrat hidroponik serta penambahan bahan anorganik terhadap perubahan sifat bagase.

\section{METODE DAN BAHAN}

Penelitian dilakukan pada bulan Agustus 2016 sampai Februari 2017 di Screen House Fakultas Pertanian Universitas Sebelas Maret, Surakarta (posisi geografi $110^{\circ} 51^{\prime} 31,4^{\prime \prime B T}$ dan $7^{\circ} 33^{\prime} 39,5^{\prime \prime}$ LS dan elevasi $95 \mathrm{~m}$ diatas permukaan laut/dpl). Percobaan menggunakan Rancangan Acak Lengkap (RAL) terdiri atas 2 faktor perlakuan. Faktor pertama adalah komposisi nutrisi terdiri atas 2 macam yaitu nutrisi standar (nutrisi Sutioso 2003) dan nutrisi modifikasi (nutrisi standar dikurangi unsur K). Faktor kedua adalah substrat terdiri atas 3 macam yaitu bagase, bagase + kerikil dan bagase + peacahan batu bata. Kombinasi kedua faktor (6 kombinasi perlakuan) masing- masing diulang 3 kali, sehingga diperoleh 18 satuan percobaan.

Kubis bunga (varietas diamond) ditanam menggunakan bahan semai dari biji berumur 2 minggu. Media tanam sesuai perlakuan di masukkan pada pollybag berukuan $30 \times 40 \mathrm{~cm}$, pada polybg dibuat lubang kecil setinggi $10 \mathrm{~cm}$ dari dasar polybag. Bagase 
dibersihkan dan direndam dalam air sebanyak $3 x$ perendaman terakhir diberi fungusida. Penyusunan substrat bagase+kerikil dan bagase+pecahan batu bata disusun berlapis, bagase di lapisan atas Volume kerikil atau pecahan batu bata sekitar $1 / 3$ bagian polybag. Pada setiap polibag di tanam 2 semai kubis bunga, setelah 1 minggu diperjarang hingga tinggal 1 tanaman. Penyiraman nutrisi dilakukan setiap 2 hari sekali sejumlah $100 \mathrm{ml}$ per tanaman. Jumlah nutrisi yang diberikan tanaman bergantung pada kondisi cuaca di lingkungan pertumbuhan tanaman (Karthikeyan et al., 2009). Pemeliharaan berupa pengendalian organisme pengganggu tanaman (OPT) secara manual dan menggunakan pestisida nabati.

Pengamatan meliputi tinggi tanaman (diukur menggunakan meteran), luas daun (dengan metode gravimetri), biomassa (menimbang tanaman setelah dioven dengan suhu $60^{\circ} \mathrm{C}$ selama 50 jam, hingga berat konstan), Panjang akar (diukur menggunakan meteran), volume akar (diperoleh dari perubahan volume air dalam gelas ukur setelah akar dimasukkan), diameter bunga (dengan jangka sorong), bobot bunga saat panen (ditimbang menggunakan timbangan digital), umur berbunga (dihitung berdasarkan hari pertama bunga tumbuh dari setelah pindah tanam).

Data yang diperoleh dianalisis dengan annova (uji $\mathrm{F}$ taraf 5\%). Jika antar perlakukan menunjukkan pengaruh nyata dilanjutkan dengan uji Duncan taraf $5 \%$.

\section{HASIL DAN PEMBAHASAN}

\section{Volume akar}

Macam media mempengaruhi pertumbuhan akar, sedangkan perbedaan nutrisi tidak menunjukkan pengaruh nyata. Pertumbuhan akar pada media bagase+kerikil dan bagase+prcahan batu bata (Gambar 1) berkisar antara 25,83 hingga $34,33 \mathrm{~mL}$, tidak berbeda nyata, kebih tinggi dari pada pada media bagase $(24,33 \mathrm{~mL})$ dan berbeda nyata.

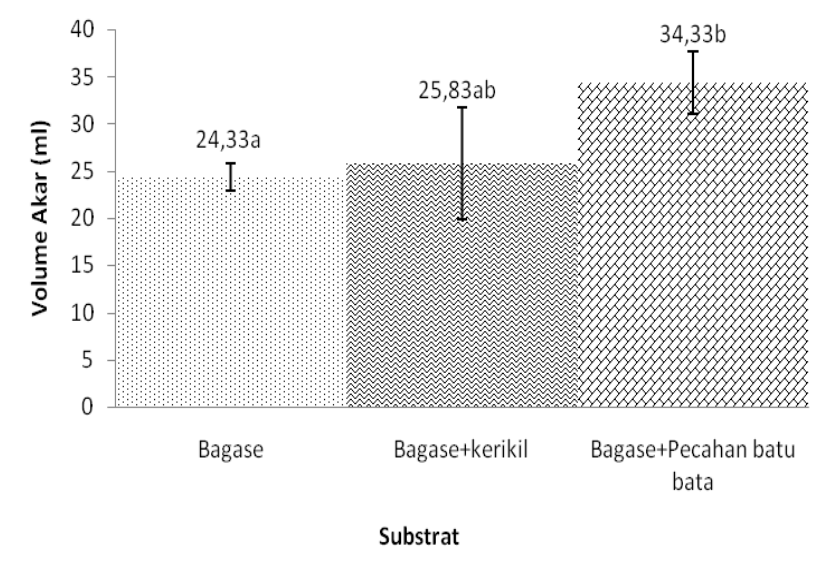

Gambar 1 Pengaruh Substrat terhadap Volume akar

Kelembaban dan aerasi suatu media sangat diperlukan untuk menunjang pertumbuhan akar, karena efektifitas pemberian nutrisi dipengaruhi oleh media tanam (Roidah 2014). Media bagase memiliki aerasi kurang bagus sehingga menurunkan ketersediaan oksigen Purnomo et al 2016 menyatakan bahwa kapasitas menahan air tinggi mengakibatkan media jenuh air. Kondisi tersebut berakibat pada kadar oksigen rendah sehingga kontak tanaman dengan oksigen terhambat, mengganggu proses respirasi mengakibatkan tanaman mengalami pembusukan akibat fermentasi. K dalam bagase tinggi dan sebagian bisa langsung diserap oleh tanaman. Nieves et al. (2013) menyatakan Kandungan K tinggi dalam media dapat diabsorpsi oleh akar tanpa seleksi oleh sistem transpor membran plasma epidermis akar dan sel korteks.

\section{Panjang akar}

Volume akar yang besar tidak mempengaruhi panjang akar, variasi nutrisi dan media tidak menunjukkan beda nyata pada panjang akar. Volume akar besar tidak disertai peningkatan panjang akar, hal ini dikarenakan sistem perakaran kubis bunga adalah serabut yang tidak lurus ke bawah (Rukmana 1994).

\section{Tinggi tanaman}

Laju pertumbuhan kubis bunga pada minggu pertama hingga minggu kedua sebesar $0,3 \mathrm{~cm}$ per hari, memasuki minggu ketiga laju pertumbuhan hanya sebesar $0,1 \mathrm{~cm}$ per hari kemudian meningkat kembali menjadi $0,3 \mathrm{~cm}$ per hari sampai umur 7 minggu, selanjutnya kembali normal dan mengalami peningkatan pada minggu $8-11$ sebesar $0.6 \mathrm{~cm}$ per hari. Pada masa awal pertumbuhan tanaman mendapat asupan karbohidrat dari kotiledon (Sitompul 2016), ketika cadangan itu habis tanaman mengalami hambatan dan setelah beradaptasi tanaman mulai tumbuh normal menggunakan fotosintat hasil fotosintesis. Tinggi tanaman menunjukkan perbedaan nyata akibat variasi media tetapi tidak demikian antar nutrisi, demikian pula interaksi antara media dan nutrisi.

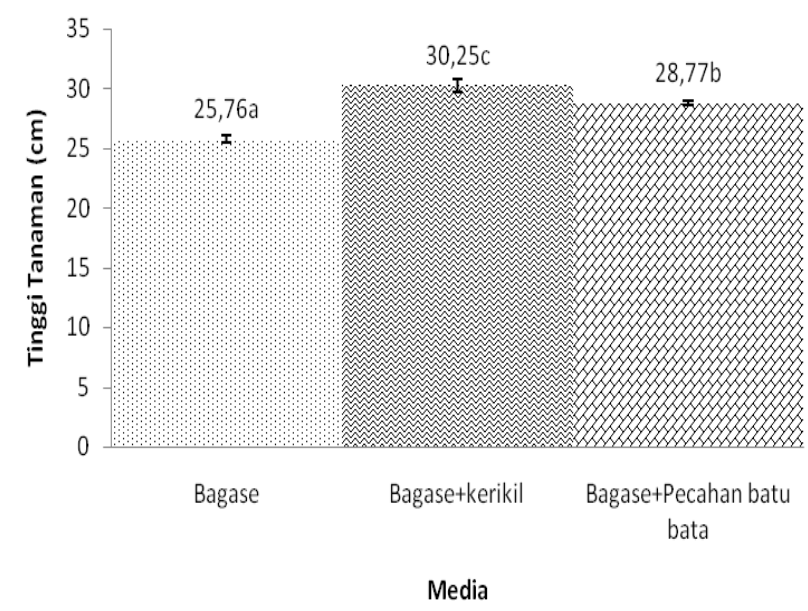

Gambar 2 Pengaruh Substrat terhadap Tinggi Tanaman

Tinggi tanaman pada media bagase, bagase+kerikil, dan bagase+pecahan batu bata berbeda nyata masingmasing mencapai 25,76, 30,25, dan 28,77 cm (Gambar 2). Tanaman pada media Kerikil merupakan material dari gunung berapi, menurut Ariyanto (2011), material gunung berapi sebagian besar pasir dan kerikil, $\mathrm{pH}$ tergolong masam (sekitar 6,32) karena masih terdapat belerang yang belum terlarut air hujan. 


\section{Luas daun}

Luas daun akan terus bertambah seiring perkembangan dan pertumbuhan tanaman. Daun berkaitan dengan proses dan laju fotosintesis tanaman. Kemampuan daun menghasilkan fotosintat ditentukan oleh total luas daun (Vidianto et al 2013). Luas daun berbeda nyata pada antar media tetapi antar nutrisi dan interaksi antara media dan nutrisi tidak berbeda nyata. Pada media bagase+pecahan batu bata luas daun mencapai 8373,54 $\mathrm{cm}^{2}$ (Gambar 3). Daun tanaman semakin luas belum tentu efektif melakukan fotosintesis karena antar daun saling menaungi. Efektifitas daun dalam proses fotosintesis terdeteksi melalui biomassa.

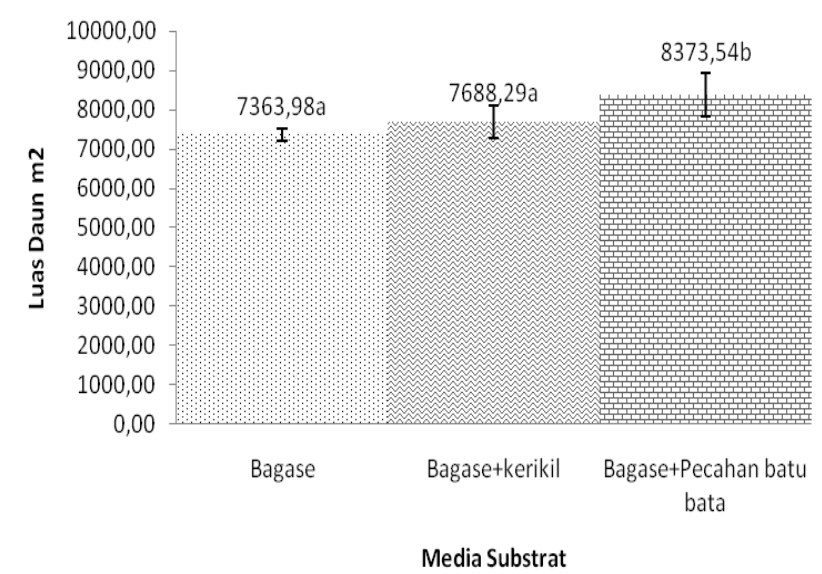

Gambar 3 Pengaruh Substrat terhadap Luas Daun

\section{Biomassa}

Biomassa terdiri atas akar, batang, dan daun berkisar antara 3,78-5,94; 12,71-15,19; 18,73-22,98 gram (Gambar 4, 5, dan 6). Biomassa akar, batang, dan daun berbeda nyata antara media tetapi tidak menunjukkan beda nyata antar nutrisi maupun interaksi antara media dan nutrisi. Biomassa adalah bahan kering, akumulasi fotosintat tanaman. Daun merupakan organ tanaman yang sangat penting dalam proses fotosintesis sehingga luas daun total rendah mengakibatkan fotosintat rendah (Danehl et al 2014).

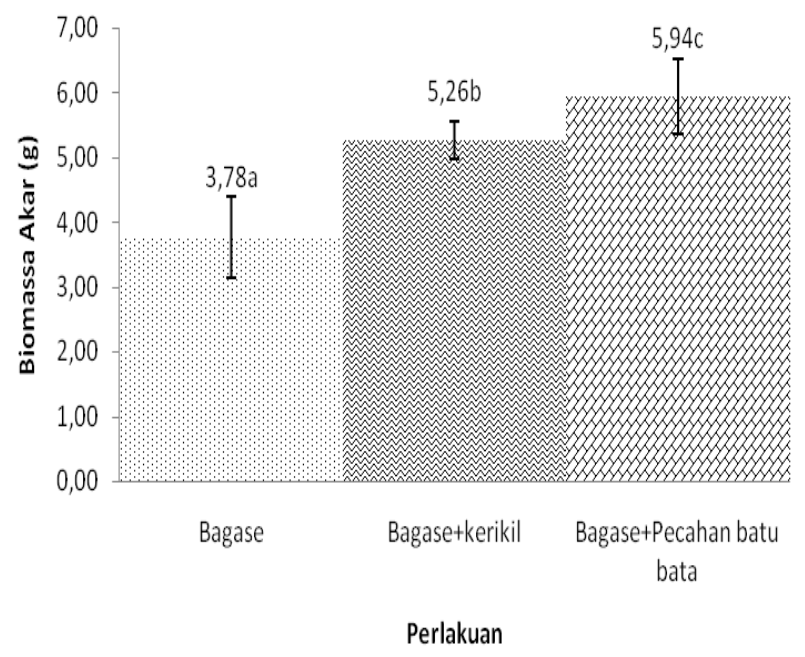

Gambar 4 Pengaruh Substrat terhadap biomasa akar

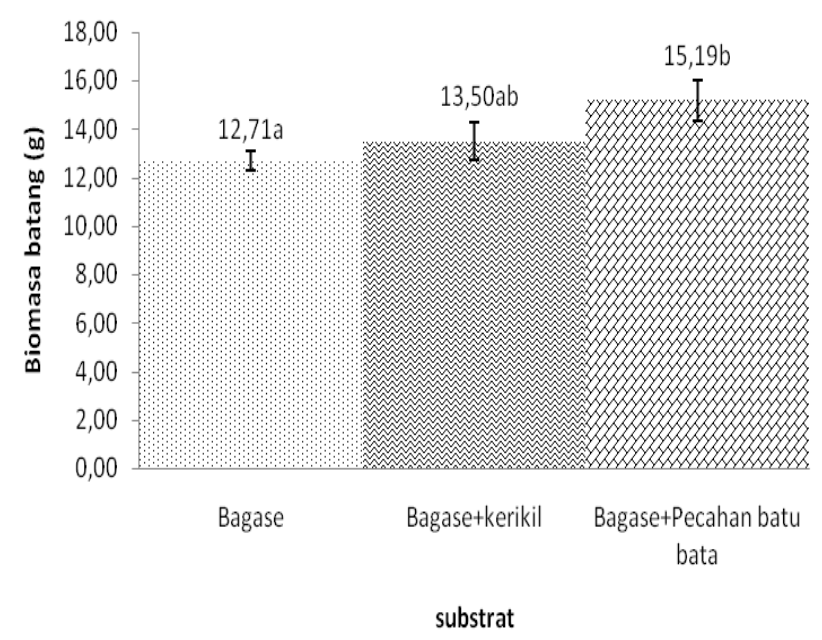

Gambar 5 Pengaruh Substrat terhadap biomasa batang

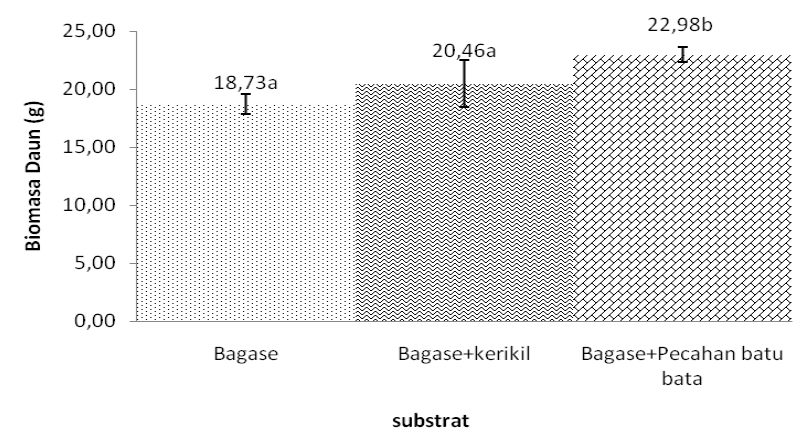

Gambar 6 Pengaruh Substrat terhadap biomasa daun

Pertumbuhan tanaman yang tercermin pada akar, tinggi tanaman, luas daun, dan biomassa menunjukkan bahwa media berperan besar. Selain tinggi tanaman variabel pertumbuhan semakin tinggi dengan penambahan kerikil dan pecahan batu bata secara berlapis pada bagase. Media tumbuh hidroponik tidak menyediakan nutrisi (Suhardiyanto 2002) sehingga kondisi fisik sangat menentukan. Penambahan pasir atau pecahan batu bata meningkatkan pertumbuhan kubis bunga melalui peningkatan kondisi fisik bagase (aerasi dan drainase), ketersediaan air karena daya penahanan air lebih tinggi (Ebrahimi et al 2012) sehingga absorpsi air dan nutrisi meningkat. Pertumbuhan akar (volume) lebih baik, absorpsi air dan nutrisi lebih tinggi menjadikan pertumbuhan lebih baik. Daun lebih luas dan biomassa (akar, batang, dan daun) lebih tinggi mengindikaskan bahwa daun efektif dalam proses fotosintesis. Akumulasi fotosintat tercermin pada biomassa tanaman (berat kering brangkasan), semakin tinggi fotosintat semakin tinggi pula biomassa (Cometti et al 2013).

\section{Umur berbunga}

Kubis bunga pada media bagase+pecahan batu bata berbunga lebih cepat sekitar 4 hari dari pada di media bagase dan bagase+kerikil (Gambar 7). Modifikasi nutrisi tidak berpengaruh nyata pada umur berbunga. Umur berbunga dapat diukur saat kuncup bunga mulai terlihat. Biasanya dimulai dari penampilan 
luar kepala sari saat bunga terbuka atau mekar (Jagadish et al 2016). Merujuk pada pertumbuhan vegetatif, kubis bunga dengan hidroponik substrat bagase labih baik, berbunga lebih cepat mengindikasikan bahwa laju pertumbuhan juga lebih cepat. Ini semakin memperkuat pembahasan bahwa penggunaan pecahan batu bata memperbaiki ketersediaan air kemudian nutrisi. Pang et al (2008) menyatakan bahwa pemberian nutrisi secara hidroponik dapat meningkatkan efisiensi penyerapan. Kecepatan pertumbuhan berdasarkan kecepatan masuk ke fase generatif berarti positif dapat dievaluasi melalui kuantitas dan kualitas hasil.

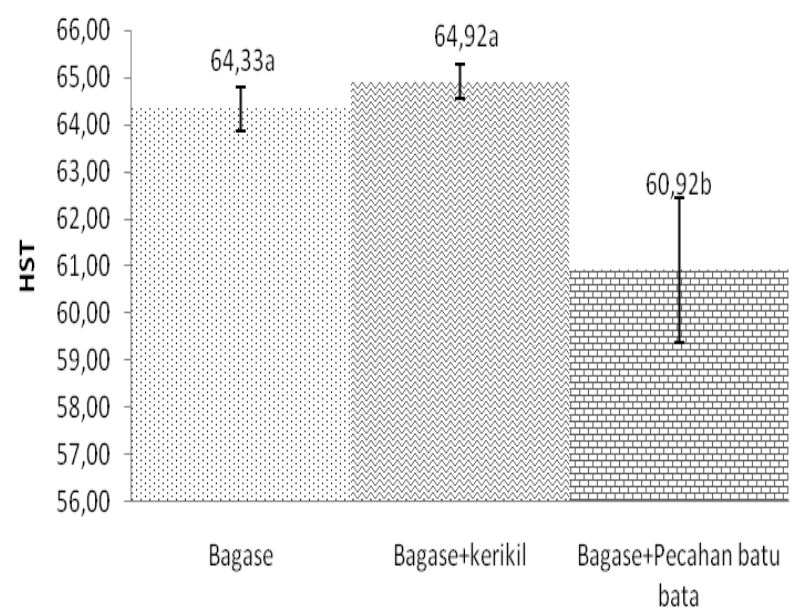

Perlakuan Media Substrat

Gambar 7 Pengaruh Substrat terhadap umur berbunga; HST: hari setelah tanam

\section{Diameter bunga}

Kualitas bunga pada kubis bunga dapat diketahui melalui pengukuran diameter bunga. Komposisi hidroponik substrat dan nutrisi tidak berpengaruh nyata terhadap diameter bunga, begitu juga interaksi antara komposisi substrat dengan nutrisi. Diameter bunga berkisar antara 10,4 -12,41 cm pada semua perlakuan menunjukkan bahwa kecepatan pembentukan bunga tidak berpengaruh pada mutu (diameter bunga). Mutu bunga menjadi lebih jelas melalui variabel bobot (secara individual atau kelompok). Rerata diameter yang terbesar di hasilkan pada perlakuan media bagase+kerikil dengan nutrisi standar yaitu sebesar $12,41 \mathrm{~cm}$. Meskipun kandungan $\mathrm{K}$ dalam media tinggi namun hanya sebagian kecil yang tersedia bagi tanaman (Zorb et al 2014). Pada media bagase+kerikil memiliki luas daun, biomassa, berat akar yang tidak terlalu tinggi, sehingga hasil fotosintat terakumulasi di bagian bunga. Menurut Siswadi (2015) jumlah fotosintat besar yang diperoleh tanaman ketika fotosintesis memungkinkan pembentukan organ tanaman yang lebih besar. Hal ini dikarenakan jumlah fotosintat yang besar terakumulasi pada organ tertentu seperti pada bunga, buah, batang dan daun. Kondisi media yang kering dan suhu di screen hause yang mencapai $38,42^{\circ} \mathrm{C}$ mengakibatkan tanaman sering layu pada siang hari. Menurut Koudela 2011 Kondisi suhu yang terlalu tinggi dan ketersediaan air pada media tanam dapat mempengaruhi hasil tanaman kubis bunga. Tanaman membutuhkan ketersediaan kalium yang tinggi yang berpengaruh terhadap hasil produksi tanaman (Miah 2008).

\section{Berat bunga}

Berat bunga adalah berat krop yang telah dipisahkan dari daun dan tangkai tanaman. Hasil analisis ragam menunjukkan bahwa komposisi substrat tidak memberikan pengaruh nyata terhadap berat bunga, nutrisi dan interaksi antara komposisi substrat dengan nutrisi. Berat bunga antara semua perlakuan hampir sama yaitu antara 91,50g-110,63g hal ini dapat dijelaskan karena pada diameter bunga tidak berbeda jauh sehingga memiliki berat bunga yang hampir sama setiap perlakuan. Berat bunga rendah dikarenakan suhu tinggi $38,42^{\circ} \mathrm{C}$ melebihi suhu optimum kubis bunga yaitu $24^{\circ} \mathrm{C}$. Suhu tinggi mengakibatkan tanaman melakukan respirasi sehingga hasil fotosintat dirombak kembali (Taiz et al 2015).

\section{Kesimpulan}

Berdasarkan analisis dan pembahasan diatas dikemukakan kesimpulan:

1. Bagase dapat digunakan sebagai media substrat hidroponik.

2. Bagase sebagai media hidroponik substrat dengan penambahan pecahan batu bata memberikan hasil pertumbuhan lebih baik.

3. Pengurangan $\mathrm{K}$ pada perlakuan nutrisi modifikasi memiliki hasil yang sama pada perlakuan nutrisi standar sehingga pengurangan tersebut dapat dilakukan.

\section{Saran}

Bagase dapat digunakan sebagai media hodroponik subtrat, pemberian nutrisi dengan pengurangan $\mathrm{K}$ dapat dilakukan.

\section{DAFTAR PUSTAKA}

Ariyanto DP, Rahayu, VR, Cahyani, Komariah. 2011. Dampak pelindihan terhadap kalsium (Ca) tertukar pada profil tanah hasil erupsi merapi tahun 2010. Prosiding Seminar Nasional "Upaya Pemulihan Lahan Akibat Erupsi Gunungapi". Jurusan IImu Tanah FP UNS. Surakarta.

Cometti NN, Diene MB, Karla G, Leonardo $\mathrm{RH}$ et al. 2013. Cooling and concentration of nutrient solution in hydroponic lettuce crop. J Hortic Bras. 31(2),

Dannehl D, J Suh, C Ulrichs, U Schmidt. 2014. Evaluation of substitutes for rock wool as growing substrate for hydroponic tomato production. $J$ of Aplied Botany and Food Quality. 88: 68-77.

Ebrahime R, M K Souri, F Ebrahime, M Ahmadizadeh. 2012. Growth and yield of strawberries under different potassium concentrations of hydroponic system in three substrates. World Applied Sciences Journal 16 (10). 
Harjoko D. 2009. Studi macam media dan debit aliran terhadap pertumbuhan dan hasil tanaman sawi (Brassica Juncea L.) secara hidroponik nft. J Agrosains. 11(2): 58-62

Jagadish SVK, Rajeev NB, Maduraimuthu D et al. 2015. Implications of high temperature and elevated co2 on flowering time in plants. $J$ Frontiers in Plant Science. 7:1-11.

Karthikeyan PK, M Ravichandran, P Imas, M Assaraf. 2009. The effect of potassium on the yield and quality of turmeric (Curcuma longa). Research Findings: e-ifc 21.

Koudela M..F. Hnilička. L. Svozilová. J. Martinková. 2011. Cauliflower qualities in two irrigation levels with the using of hydrophilic agent. Hort. Sci. (Prague). Vol.38,No.2:81-85

Miah, M.A.M., P.K. Shaha, A. Islam, M.N. Hasan, and V. Nosov. 2008. Potassium Fertilization in Rice-Rice and Rice-Wheat Cropping System in Bangladesh. Bangladesh J. Agric. and Environ. 4:51-67.

Nieves CM., F. Aleman, V. Martinez, and F. Rubio. 2013. K+ Uptake in Plant Root. The System Involved, They Regulation and Parallels in Other Organisms. J. of Plant Physiol. 175: 688-695

Pang, J, H. Sun, A. Nduwimana, Y. Wang, G. Zhou, Y. Ying dan R. Zhang. 2008. Hydroponic plate/fabric/grass system for treatment of aquacultural wastewater. J Aquacultural Engineering. 38 (1): 77.

Purnomo D. Harjoko D. Sulistyo TD. Budidaya Cabai Rawit Sistem Hidroponik Substrat Dengan Variasi

69.
Media dan Nutrisi. J.of Sustainable Agriculture. Vol 31. No 2;129-136.

Roidah Ida S. 2014. Pemanfaatan Lahan Dengan Menggunakan Sistem Hidroponik .J. Universitas Tulungagung Bonorowo. Vol. 1.No.2

Samsuri, Gozan M, Mardias R et al. 2007. Pemanfaatan selulosa bagasse untuk produksi ethanol melalui sakarifikasi dan fermentasi serentak dengan enzym xylanse. J. Makara Teknologi . Vol.11(1).

Siswadi dan Teguh Y. 2015. Uji Hasil Tanaman Sawi Pada Berbagai Media Tanam Secara Hidroponik. Jurnal Innofarm Vol. II(1).

Sitompul, S M. 2016. Analisis Pertumbuhan Tanaman. Malang. UB Press

Suhardiyanto S. 2002. Teknologi hidroponik dalam pelatihan aplikasi teknologi hidroponik untuk pengembangan agribisnis perkotaan. Creata-IPB: Bogor. pp 1-12.

Sutiyoso Y. 2003. Meramu pupuk hidroponik tanaman sayur, tanaman buah, tanaman bunga. Jakarta (ID): Penebar Swadaya.

Taiz L, Eduardo Z, lan MM et al. 2015. Plant physiology and development. Sinauer Associates

Vidianto D. Z. S. Fatimah. C. Wasonowati. 2013. Penerapan Panjang Talang Dan Jarak Tanam dengan Sistem Hidroponik $\mathrm{Nft}$ (Nutrient Film Technique) Pada Tanaman Kailan (Brassica Oleraceae Var. Alboglabra).J. Agrovigor. Vol.6 No.2

Zorb C., M. Seinbayram, and E. Peiter. 2014. Potassium in Agriculture-status and Perspectives. J. of Plant Physiol. 171:656-6 